\title{
Study of a membrane bioreactor with glass fiber flat grille modules and the modules' optimization based on the local critical flux theory
}

\author{
Dongdong Yuan, Yaobo Fan*, Yan Yu, Guoliang Xu, Wenjing Yang, Guangxia Wu \\ Department of Water Pollution Control Technology, Research Center for Eco-Environmental Sciences, Chinese Academy of Sciences, \\ 18 Shuangqing Road, Haidian District, Beijing 100085, China
}

\section{A R T I C L E I N F O}

Article history:

Received 5 June 2009

Received in revised form

2 September 2009

Accepted 18 October 2009

Available online 27 October 2009

Keywords:

Inorganic glass fiber

MBR

Module configuration

Surface modification

Local critical flux

Critical time

\begin{abstract}
A B S T R A C T
A novel flat grille membrane module using inorganic glass fibers as filter media is proposed for use in a membrane bioreactor for wastewater treatment. A model which integrates the concepts of back transport velocity, spatial local critical flux and temporal variation of the local flux has been developed. The membrane module was optimized based on experimental results and calculations using the model. The optimized parameters include the volume ratio of membrane solution for the surface modification of glass fibers, the fiber inner diameter and fiber length. The optimal values were $1: 2$ and $5 \mathrm{~mm}$ respectively but the length had little effect on the performance of the module. The critical time was then calculated with the model and an equation developed. The result was in very good agreement with the observed one. Finally, the performance of the glass fiber MBR was monitored. The effluent quality and stability of the system were comparable to that of conventional MBRs. This MBR will be a promising technique for wastewater treatment given its low cost, high strength and good effluent quality.
\end{abstract}

(c) 2009 Elsevier Ltd. All rights reserved.

\section{Introduction}

In recent years, the membrane bioreactor (MBR) process, which is considered to be a good integration of the conventional activated sludge (CAS) system and the micro-filtration (MF) or ultrafiltration (UF) membrane separation processes (Williams and Pirbazari, 2007), has gained worldwide attraction and popularity due to its small footprint, low sludge production and good effluent quality (Wang et al., 2006). According to a technical market research report (Hanft, 2006), the global market for membrane bioreactor is rising at an average annual growth rate of $10.9 \%$, and is expected to approach US\$363 million in 2010 with the market for membrane modules up to US\$157 million.
However, there are three major drawbacks preventing the wide application of this process, including high cost of membrane modules, low membrane strength especially for hollow fibers and the potential rapid loss of performance due to membrane fouling (Fan and Huang, 2002; Zhou et al., 2008). The dynamic membrane bioreactor (DMBR) process, which usually uses mesh, no woven fabric, and filter-cloth as filter media, is one of the solutions to these problems. The dynamic membrane is also known as secondary membrane or formed-in-place membrane. When filtering a feed solution containing fine particles, a dynamic or secondary layer of rejected particles is formed on the underlying primary filter surface (Kuberkar and Davis, 2000). Once the membrane has become severely fouled, the dynamic layer can be replaced by a new deposited layer, that

\footnotetext{
* Corresponding author. Tel./fax: +86 1062849108.

E-mail address: yaobofan@hotmail.com (Y. Fan).

0043-1354/\$ - see front matter (c) 2009 Elsevier Ltd. All rights reserved.

doi:10.1016/j.watres.2009.10.015
} 
a

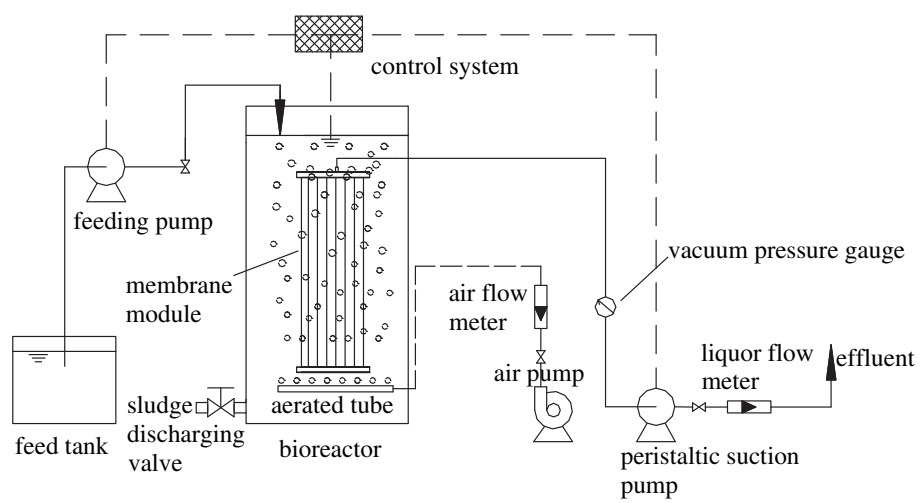

b

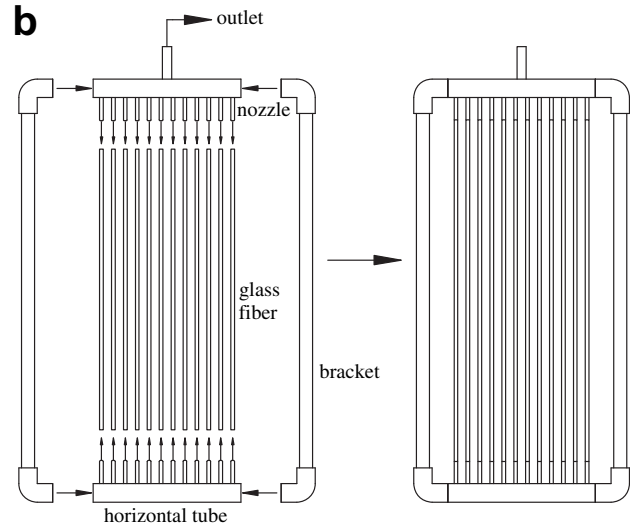

Fig. 1 - Schematic diagram of the MBR and the module. (a) The experimental system; (b) the configuration and fabrication of flat grille modules.

is, the cleaning and regeneration of the dynamic membrane are simple to achieve. Therefore, the costs of purchasing and physically replacing new membranes are avoided (Chu and Li, 2006; Kiso et al., 2002; Al-Moghaddam et al., 2002). However, DMBRs have also several disadvantages. For example, although the initial flux of DMBR is high it declines rapidly and thus frequent backwashing is necessary; the effluent quality is unstable especially after regeneration; the main module configuration applied in DMBRs is flat sheets for which the packing density is low. Moreover, it is notable that traditional organic membranes and filter media use non-renewable oil as a raw material. It is foreseeable that with the increasing scarcity of oil resources, the application of organic membranes will be limited.

Moreover, the critical flux hypothesis has been extensively applied to all membrane systems (Guglielmi et al., 2007), with the aim of reducing membrane fouling rate and maintain MBR performance. The critical flux hypothesis was presented originally by Field et al. in 1995 (Field et al., 1995) and two distinct forms of the concept have been defined. In the strong form, the sub-critical flux is equal to the clean water flux obtained under the same conditions. In the alternative weak form, the subcritical flux is the flux that rapidly established and maintained during the start-up of the filtration, but not necessarily equal to the clean water flux (Wu et al., 1999). Due to the initial membrane fouling and complex nature of the activated sludge within MBRs, such as large particle size distributions and the presence of extracellular polymeric substances (EPSs), the weak form is normally applied to MBR processes (Le-Clech et al., 2003a,b; Ognier et al., 2004). The critical flux value depends on

\section{Table 1 - Influent wastewater characteristics of the MBR.}

Parameters

Concentration

(mg L ${ }^{-1}$ except $\mathrm{pH}$ )

\begin{tabular}{ll}
\hline $\mathrm{COD}$ & $161.12-411.49$ \\
$\mathrm{BOD}_{5}$ & $40-140$ \\
$\mathrm{NH}_{4}^{+}-\mathrm{N}$ & $46-140$ \\
$\mathrm{TN}$ & $100-160$ \\
$\mathrm{TP}$ & $4-15$ \\
$\mathrm{pH}$ & $7.03-7.85$ \\
\hline
\end{tabular}

the characteristics of the membrane (pore diameter, porosity, and materials), those of the activated sludge (nature, particle size distribution in relation to pore size distribution, and sludge concentration) and the hydrodynamic operation conditions (Ognier et al., 2004; Le-Clech et al., 2003a,b; Bacchin et al., 2005). However, in previous works, the factors influencing the critical flux were often qualitatively described and determined through experimental methods. In order to improve the performance of MBRs, mathematical methods should be introduced to determine the critical flux and critical time.

To deal with the above problems, an inorganic glass fiber has been introduced as the filter medium and a novel membrane module in the form of flat grilles has been developed. Based on the concepts of spatial flux distribution and temporal variation of the local flux in an open pore, a model has been developed to describe the function of MBRs. Following analysis using this model, the membrane module was optimized, including the surface modification of the glass fibers to improve their porosity, and determination of the best inner diameter and length for the glass fibers. Furthermore, the critical time was calculated based on the model and validated from experimental results. Finally the performance characteristics of the MBR were monitored in order to examine the efficiency of the treatment.

\section{Materials and methods}

\subsection{Experimental setup}

As shown in Fig. 1(a), the experimental system basically consisted of an activated sludge bioreactor in which membrane modules were submerged. The effective volume of the bioreactor was $34.2 \mathrm{~L}$. A water level controller was used to switch the feeding pump on and off to maintain a constant water level in the bioreactor tank. The influent of the bioreactor was raw sewage from research center of eco-environmental Chinese Academy of Sciences. The characteristics of the raw wastewater are listed in Table 1. The effluent was drawn from the DMBR by a peristaltic suction pump, which was operated in an intermittent mode with 5 min on and 2 min off. Air was provided through perforated pipes located at the bottom of the 


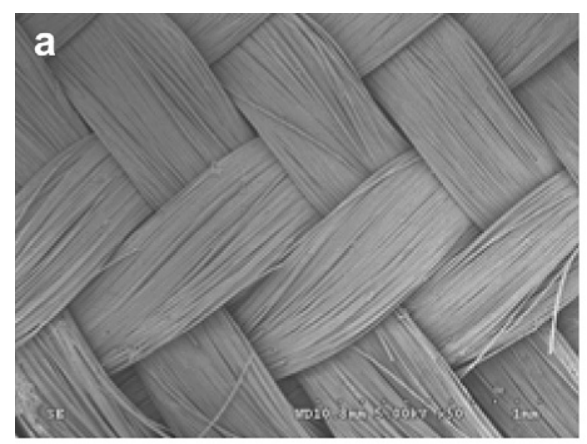

without modification

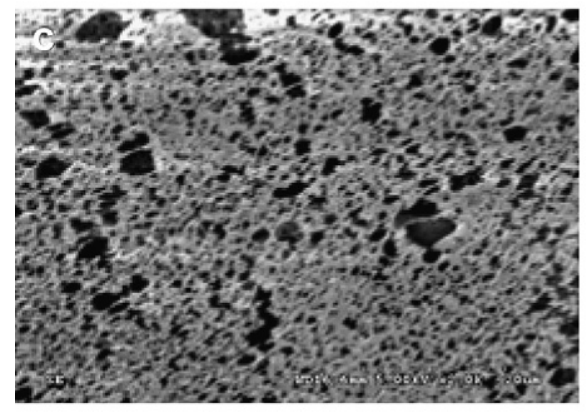

volume ratio $=1: 3$

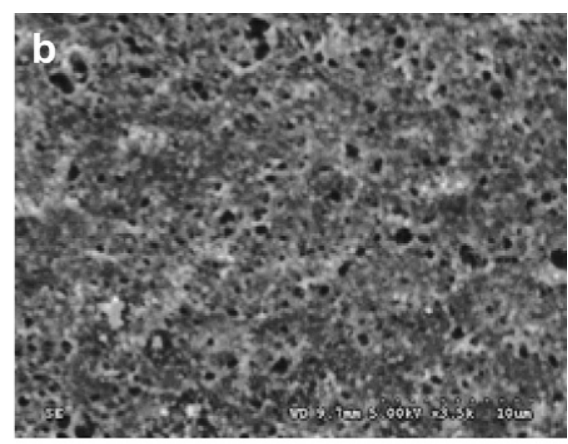

volume ratio $=1: 2$

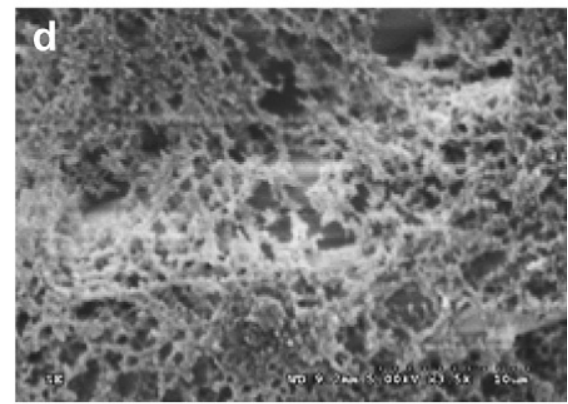

volume ratio $=1: 4$

Fig. 2 - SEM images of glass fiber tubes before and after modification.

modules whose pore size was $1 \mathrm{~mm}$. The flow rate was maintained at $0.8 \mathrm{~m}^{3} / \mathrm{h}$.

\subsection{The design of the membrane module}

The module configuration defines not only the membrane arrangement, the packing density, the filtration mode and the hydraulic distribution throughout the membrane network, but also the energy requirement and ease of membrane regeneration. Accordingly, the optimization of the module configuration is of great significance. Based on a synthesis of the characteristics of flat sheet modules and hollow fiber modules (Fane, 2002), a novel flat grille module using glass fibers as filter media has been designed (Fig. 1(b)). Inorganic glass fibers have the advantages of low price (about $\$ 8 / \mathrm{m}^{2}$ ), high strength and excellent chemical stability. This type of module resembles flat sheets with the degree of fiber tightness at $100 \%$, giving them good flow channels for gas-liquid flow and high strength because flat sheet modules were not swinging (Cui et al., 2003). By adjusting the space between the glass fibers, the packing density could be made almost the same as that of hollow fiber modules and higher than that of flat sheets (Yeo et al., 2006). The operational mode of the module was similar to that of hollow fibers, which was that the effluent flowed through the lumen of glass fibers and pooled into the horizontal tube. It was worth mentioning that both ends of every glass fiber were sheathed by the corresponding nozzles as shown in Fig. 1(b). This method was different from the traditional casting method used to fabricate hollow fiber modules and avoided the mixed liquor leaking into the effluent.

\subsection{Analytical methods}

\subsubsection{The analysis of local membrane fouling}

At the end of a long-term filtration, the fouled membranes were taken out of the system, the foulants were analyzed and the local membrane resistance was determined. The fibers were sampled at three locations, approximately $0.02,0.22$ and $0.42 \mathrm{~m}$ from the fiber outlet (total fiber length of $0.52 \mathrm{~m}$ ) and an unfouled fiber was sampled as a control. The length of each sample was $5 \mathrm{~cm}$. The total dry mass of foulants was determined by subtracting the mass of unfouled fiber sample from the mass of dry fouled sample. The local membrane resistance was estimated by measuring the water flux of de-ionized water according to Darcy's law.

\subsubsection{Flux-stepping method for critical flux assessment}

The critical flux can be obtained from flux-TMP measurements by flux or pressure stepping, the hysteresis method, and direct observation through the membrane (DOTM) (Bacchin et al., 2006; Howell et al., 2004; Defrance and Jaffrin, 1999). The flux-stepping method has advantages over others and, accordingly, this method was chosen to determine the critical flux. In planning flux-step tests, the duration of each step and the step size play important roles, as they determine the duration of the whole test. In our case, a step duration of $15 \mathrm{~min}$ was chosen with a step height of about $2-4 \mathrm{~L} \mathrm{~m}^{-2} \mathrm{~h}^{-1}$, no permeation stoppage occurred during the flux-step tests. The results were evaluated in terms of the TMP-based parameters as proposed by Le-Clech et al. (2003a,b) and recently integrated by Guglielmi et al. (2007). 


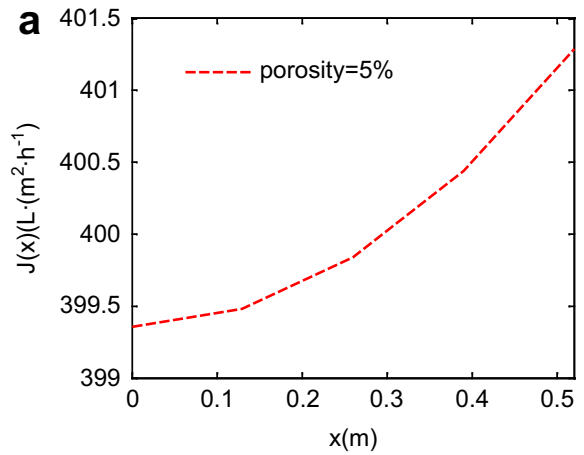

without modification

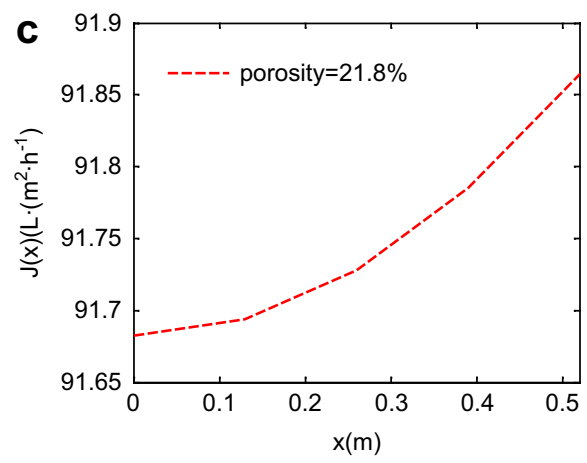

volume ratio $=1: 3$

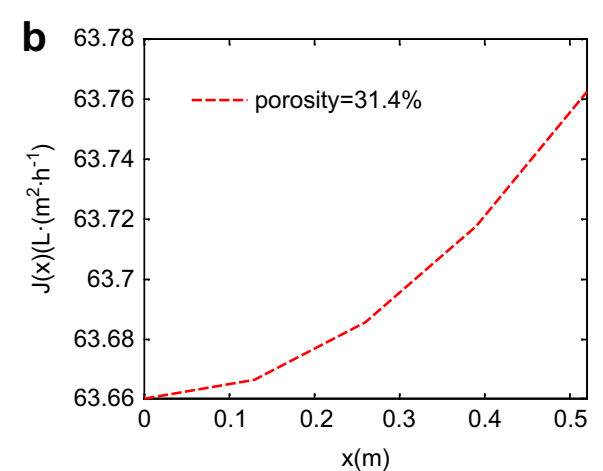

volume ratio $=1: 2$

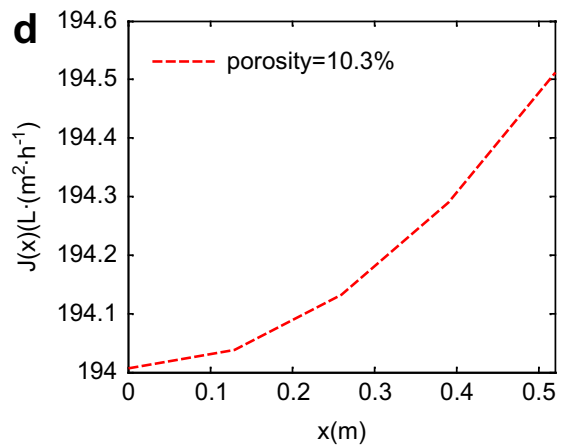

volume ratio $=1: 4$

Fig. 3 - Simulated flux distribution along a fiber.

\subsubsection{Other items}

The parameters $\mathrm{COD}, \mathrm{BOD}_{5}, \mathrm{NH}_{3}-\mathrm{N}, \mathrm{pH}$ and mixed liquor suspended solid (MLSS) concentrations were measured, according to Chinese SEPA standard methods (China EPA, 2002). The supernatant was obtained by centrifuging the mixed liquor at $4000 \mathrm{rpm}$ for $15 \mathrm{~min}$, followed by filtration through a membrane with $0.45 \mu \mathrm{m}$ pore size. The dissolved oxygen (DO) concentration was measured using a DO meter (Orion 080514, Thermo electron Corporation, USA). The turbidity was evaluated using a Hanna LP2000 turbidity instrument. A propeller flow velocity meter (LS45A, Chongqing Hydrological Apparatus Manufacture of the Hydraulic Ministry) was used to measure the flow velocities through membrane surface. The observed flow velocity was an average of five-measured values. The sludge particle size distribution of the mixed liquor was determined by a Laser Particle sizer (Mastersizer 2000, Malvern, USA). The EPS extraction was carried out according to the method introduced by Ji and Zhou (2006). Both free and bound forms of EPS were analyzed in a spectrophotometer for polysaccharide and protein contents. The former were measured by the anthrone method with glucose as standards, and the latter were measured by the Lowry method with bovine serum albumin as the reference protein.

2.3.4. A model based on the concepts of the spatial local flux distribution and temporal variation of the local flux

During the sub-critical operating condition of MBRs, slow membrane fouling and reduction of the open pore area still take place because free and bound forms of EPS interact with the membrane. It is assumed that the rate of reduction in the effective area is proportional to the mass of free EPS $\left(C_{\mathrm{f}} \mathrm{Q}\right)$ and bound EPS $\left(C_{b} Q\right)$ and is relevant to the permeate flux flow $Q$ (Guglielmi et al., 2007). In mathematical terms:

$\frac{\mathrm{dA}}{\mathrm{d} t}=k\left(C_{\mathrm{f}} \mathrm{Q}\right)\left(C_{\mathrm{b}} \mathrm{Q}\right)$

where $k$ is a coefficient of fouling propensity.

In submerged hollow fiber MBRs, the flux along a vertical hollow fiber is inhomogeneous and thus the fouling rate varies along the fiber (Chang and Fane, 2001, 2002). Based on this view, a mathematical model to predict local flux distribution in an open pore is proposed. Then the critical time $\left(t_{\text {crit }}\right)$, when the TMP increases abruptly, is determined.

A model has been proposed describing the spatial profile of the flux distribution along a fiber (Chang and Fane, 2001, 2002). It is expressed as:

$J(x)=\frac{(h+l-x) g \rho-p(x)}{\mu R_{m}}=\frac{\lambda l J_{m i}}{\mathrm{e}^{\lambda l}-\mathrm{e}^{-\lambda l}}\left(\mathrm{e}^{\lambda x}+\mathrm{e}^{-\lambda x}\right)$

where $R_{\mathrm{i}}$ is the fiber inner radius, $R_{\mathrm{m}}$ is the resistance of the fiber, $J_{\mathrm{mi}}$ is the average imposed flux, $l$ is the fiber length, $x$ is the distance from the dead end of a fiber and

$\lambda=\sqrt{\frac{16}{R_{\mathrm{i}}^{3} R_{\mathrm{m}}}}$

This equation is based on the hypothesis that the total apparent area of a fiber is permeable and the corresponding 
Table 2 - Experimental and the simulated apparent critical fluxes.

\begin{tabular}{lcccc} 
Volume ratio & $\begin{array}{c}\mathrm{R}_{\mathrm{m}} \\
\left(\times 10^{10}\right)\end{array}$ & $\lambda$ & $\begin{array}{c}\text { Experimental } \\
\text { values } \\
\left(\mathrm{L} \mathrm{m}^{-2} \mathrm{~h}^{-1}\right)\end{array}$ & $\begin{array}{c}\text { Simulated } \\
\text { values } \\
\left(\mathrm{L} \mathrm{m}^{-2} \mathrm{~h}^{-1}\right)\end{array}$ \\
\hline $\begin{array}{l}\text { Without } \\
\quad \text { modification }\end{array}$ & 2.87 & 0.189 & 8.82 & - \\
$\begin{array}{l}1: 2 \\
1: 3\end{array}$ & 8.60 & 0.1091 & 48.3 & 55.5 \\
$1: 4$ & 6.96 & 0.1213 & 33.6 & 38.5 \\
& 5.32 & 0.1387 & 23.5 & 18.2 \\
\hline
\end{tabular}

flux $J(x)$ is the apparent value. Actually, not all the apparent membrane area is permeable, but there is a degree of porosity and the local (or actual) flux in an open pore is greater than the apparent value. This can be explained as follows.

As the permeate flow is held constant during the experimental run, the flow $Q$ can be expressed as:

$Q=\int_{A} J_{1}(x) d A_{e}=\int_{A} J_{1}(x) d\left(\varepsilon A_{a}\right)=\int_{A} \varepsilon J_{1}(x) d A_{a}$

It also can be expressed as:

$\mathrm{Q}=\int_{\mathrm{A}} J(\mathrm{x}) \mathrm{d} \mathrm{A}_{\mathrm{a}}=p_{i} \mathrm{~d}_{\mathrm{i}} \mathrm{lJmi}=\mathrm{A}_{\mathrm{a}} \mathrm{J}_{\mathrm{mi}}$

where $J(x)$ and $J_{1}(x)$ are the apparent flux distribution and the local (or actual) flux distribution along a fiber, respectively, $A_{e}$ is the effective area available for filtration, $A_{a}$ is the apparent area of a fiber. And the porosity $\varepsilon$ is defined as:

$\varepsilon=\frac{A_{e}}{A_{a}}$

Comparing Eq. (4) with Eq. (5), it can be concluded that:

$\varepsilon J_{1}(x)=J(x)=\frac{\lambda l J_{\mathrm{mi}}}{\mathrm{e}^{\lambda l}-\mathrm{e}^{-\lambda l}}\left(\mathrm{e}^{\lambda x}+\mathrm{e}^{-\lambda x}\right)$

Thus a new model is put forward as:

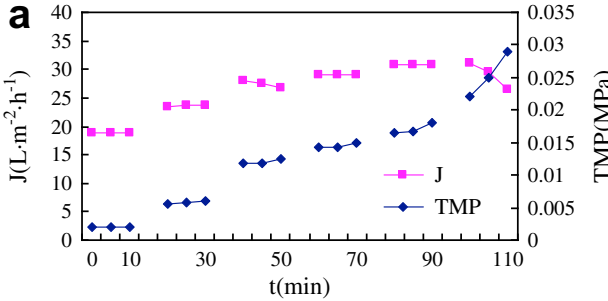

without modification

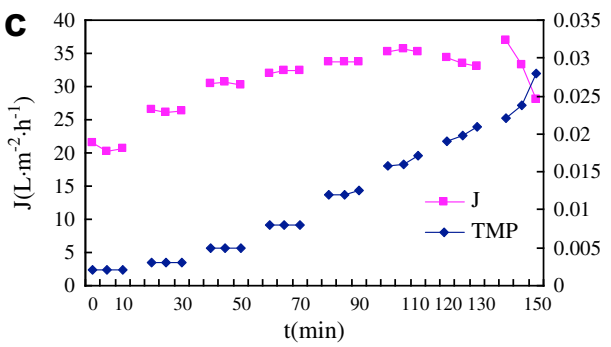

volume ratio $=1: 3$
$J_{l}(x)=\frac{\lambda l J_{m i}}{e^{\lambda l}-e^{-\lambda l}}\left(e^{\lambda x}+e^{-\lambda x}\right) \frac{1}{\varepsilon}$

This model combines the profile of flux distribution along a fiber with the local flux by the introduction of the parameter $\varepsilon$. According to this model, the local flux reaches its maximum at the outlet and is inversely proportional to $\varepsilon$. When the value of $\varepsilon$ is reduced to an extent because of the gradual fouling of the membrane (Guglielmi et al., 2007), the local flux at the outlet increases gradually to the point at which when the system reaches the critical state. This state can be explained by the radial balance of forces on a particle. When the forces dragging particles to the membrane are equal to the forces driving the particles off the membrane (Madecl et al., 2008), the critical state occurs, and the critical flux is the rate of particle convection towards the membrane surface which is balanced by the back transport velocity. An equation for the back transport velocity was proposed by Shimizu as a function of the operating parameters of $u$ and the mixed liquor characteristics of $C_{\mathrm{p}}, d_{\mathrm{p}}$ and $\eta$ (Shimizu et al., 1993), expressed as:

$\mathrm{V}_{\mathrm{L}}=\mathrm{K}_{\mathrm{L}} \cdot \mathrm{u}^{1.0} \cdot \mathrm{C}_{\mathrm{p}}^{-0.5} \cdot d_{\mathrm{p}}^{0.67} \cdot \eta^{-1.0}$

where $V_{\mathrm{L}}\left(\mathrm{m} \mathrm{s}^{-1}\right)$ is the back transport velocity, $K_{\mathrm{L}}$ $\left(\mathrm{kg}^{0.5} \mathrm{~m}^{-2.17} \mathrm{~Pa} \mathrm{~s}\right)$ is the filtration constant, $u\left(\mathrm{~m} \mathrm{~s}^{-1}\right)$ is the flow velocity through the membrane surface, $C_{p}\left(\mathrm{~kg} \mathrm{~m}^{-3}\right)$ is the particle concentration, $d_{\mathrm{p}}(\mathrm{m})$ is the particle size and $\eta(\mathrm{Pa} \mathrm{s})$ is the viscosity. This equilibrium state is reached at what is called the critical time when the trans-membrane pressure starts to increase abruptly (Ho and Zydney, 2000; Saroj et al., 2008). The simulated critical time can be calculated according to Eq. (1):

$T_{\text {crit }}=\frac{A_{e}(0)-A_{e}(\text { crit })}{k Q^{2} C_{b} C_{f}}$

where $A_{\mathrm{e}}$ (crit) corresponds to the value of $\varepsilon$ when the critical state is reached.

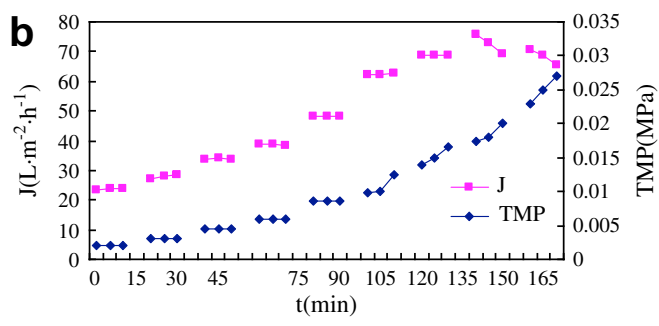

volume ratio $=1: 2$

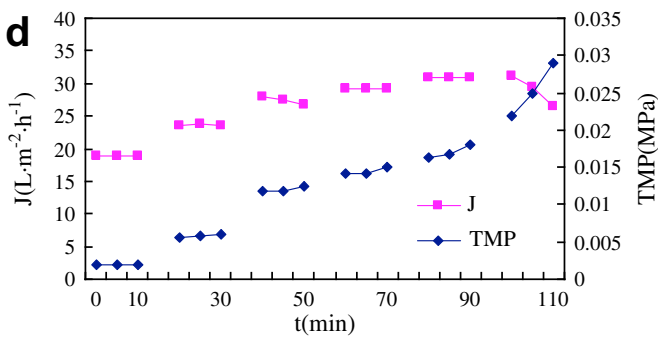

volume ratio $=1: 4$

Fig. 4 - Schematic representation of the critical flux determination by the flux-step method. 


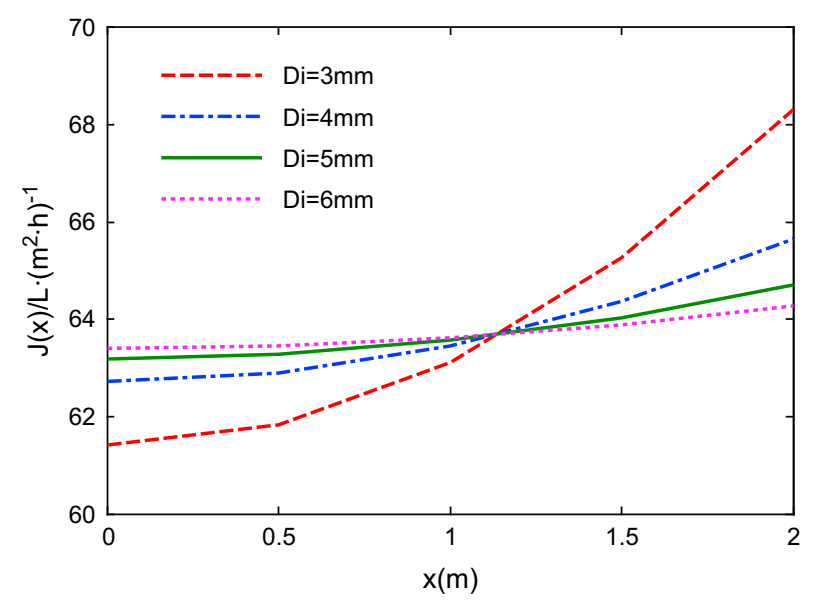

Fig. 5 - Simulated effect of inner diameter on difference of flux along the fiber.

\section{Results and discussion}

\subsection{Optimization of the flat grille module}

\subsubsection{The effect of membrane porosity}

Eq. (8) shows that the membrane porosity has a significant effect on the local flux in an open pore. The simulated flux distribution along the glass fiber with a porosity of $5 \%$ (see Fig. 2(a)) is illustrated in Fig. 3(a), which shows that the local flux increases with $x$ and reaches its maximum of $418.87 \mathrm{~L} /$ $\left(\mathrm{m}^{2} \mathrm{~h}\right)$ at the outlet of a fiber. It is assumed that when the local flux at the outlet is equal to the back transport velocity $V_{L}$, the system comes into the critical state. The corresponding $V_{L}$ of the given mixed liquor used in our experiment was just $177.0 \mathrm{~L} \mathrm{~m}^{-2} \mathrm{~h}^{-1}$, according to Eq. (9), with parameters $K_{\mathrm{L}}$, $d_{\mathrm{p}}(0.5), u, C_{\mathrm{p}}, \eta$ equal to $1.4 \times 10^{-3} \mathrm{~kg}^{0.5} \mathrm{~m}^{-2.17} \mathrm{~Pa} \mathrm{~s}, 45.841 \mu \mathrm{m}$, $0.15 \mathrm{~m} \mathrm{~s}^{-1}, 7.0 \mathrm{gL}^{-1}$ and $2.0 \mathrm{mPa}$, respectively. $d_{\mathrm{p}}(0.5)$ represents the particle size when the volume ratio is $50 \%$ and is regarded as the average particle size of the activated sludge. The observed flow velocity $u$ was the average of five-measured values and $K_{L}$ was determined by combining Eqs. (8) and (9), in which $x$ was set equal to l, with the experimentally observed critical flux of the unmodified glass fiber module (see Table 2 and Fig. 4(a)). Thus it was reasonable to expect that the system was running in supra-critical zone when $J_{\mathrm{mi}}$ was equal to $20 \mathrm{~L} \mathrm{~m}^{-2} \mathrm{~h}^{-1}$.

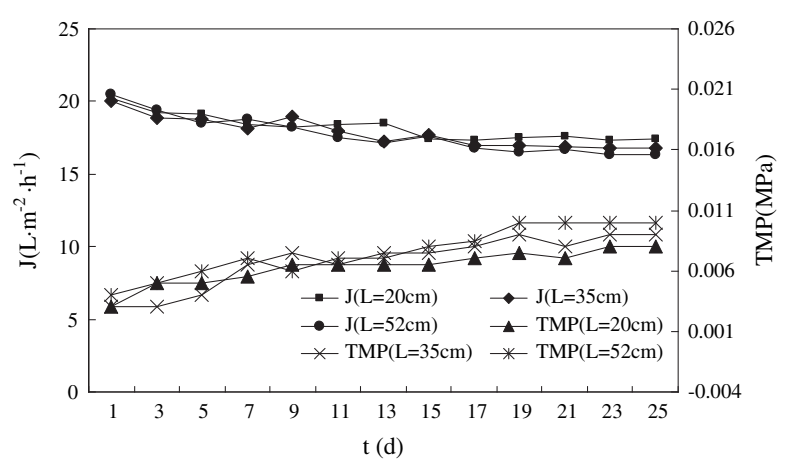

Fig. 6 - Membrane flux and TMP of different fiber length.

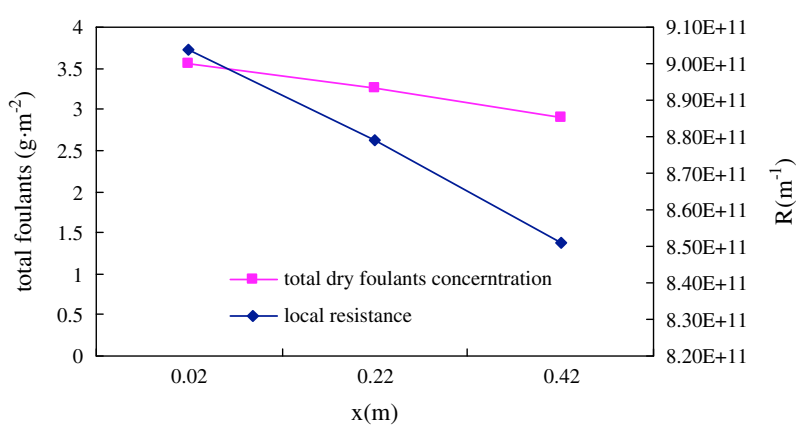

Fig. 7 - Spatial distribution of total foulants and local membrane resistance.

In order to improve the porosity of glass fibers, their surface was modified by coating with an organic membrane solution. The glass fibers could then be reused if the membrane solution became detached after a period of time. This solution was constituted of membrane materials and the solvent dimethylacetamide (DMAC). The volume ratio of membrane material to DMAC was 1:2, 1:3 and 1:4 respectively with corresponding porosities of $31.4 \%, 21.8 \%$ and $10.3 \%$. Using Eqs. (8) and (9) with $x$ equal to $l$, the simulated apparent critical fluxes were calculated (Table 2) and were found to be in fine agreement with the experimental results, as shown in Table 2 and Fig. 4(b-d). There is a slight underestimate or overestimate, especially for the volume ratio of 1:4. Moreover, Fig. 3(b-d) shows the local flux distribution after the surface modification. It illustrates that the flux profiles are more even and the local flux is lower than the back transport velocity, except for the case where the volume ratio is equal to 1:4. Therefore the surface modification is effective in improving the apparent critical fluxes and the flux distribution along a fiber. Considering the above factors and others such as membrane strength, the best volume ratio of 1:2 is chosen and only this ratio is used in the following experiments.

\subsubsection{Effect of the fiber's inner diameter}

As mentioned above the pressure drop in the fiber tends to cause a distribution of flux with the highest at the lumen outlet. To ensure nearly equal filtration in all segments of the fiber, the maximum flux difference in the axial direction should be restricted to below $5 \%$ and thus all segments of the

Table 3 - Parameters for model calibration.

\begin{tabular}{lllll} 
Parameter & \multicolumn{2}{c}{ Symbol } & \multicolumn{1}{c}{ Unit } & Value \\
\hline Permeate & Test 1 & $\mathrm{Q}_{1}$ & $\mathrm{~L} \mathrm{~h}^{-1}$ & 3.30 \\
& Test 2 & $\mathrm{Q}_{2}$ & $\mathrm{~L} \mathrm{~h}^{-1}$ & 1.72 \\
Apparent membrane area & $\mathrm{A}_{\mathrm{a}}$ & & $\mathrm{m}^{2}$ & 0.11 \\
Apparent critical flux & $J_{\mathrm{mi}}(\mathrm{crit})$ & & $\mathrm{L} \mathrm{m}^{-2} \mathrm{~h}^{-1}$ & 48.3 \\
Local critical flux & $\mathrm{J}(\mathrm{x}=1)$ & & $\mathrm{L} \mathrm{m}^{-2} \mathrm{~h}^{-1}$ & 154.0 \\
Porosity corresponding & Test 1 & $\varepsilon_{\mathrm{c} 1}$ & - & $19.50 \%$ \\
$\quad$ to critical time & Test 2 & $\varepsilon_{\mathrm{c} 2}$ & - & $10.14 \%$ \\
Bound EPS & $\mathrm{C}_{\mathrm{b}}$ & & $\mathrm{g} \mathrm{m}^{-3}$ & $29.2 \pm 2.1$ \\
Free EPS & $\mathrm{C}_{\mathrm{f}}$ & & $\mathrm{g} \mathrm{m}^{-3}$ & $9.3 \pm 0.9$ \\
Coefficient of fouling & $\mathrm{K}$ & & $\mathrm{m}^{2} \mathrm{~h} \mathrm{~g}^{-2}$ & $1.39 \times 10^{-2}$ \\
$\quad$ propensity & & & & \\
\hline
\end{tabular}




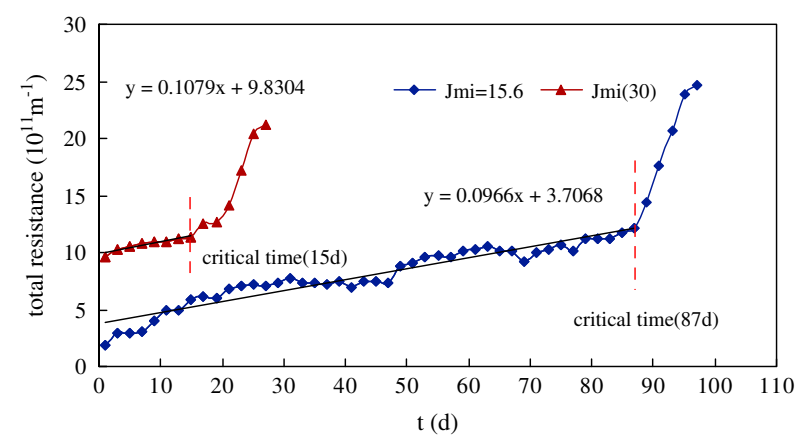

Fig. 8 - Membrane resistance profiles for tests 1 and 2.

fiber will be similarly fouled during the course of the filtration (Fane et al., 2002; Yoon et al., 2004).

The difference of flux along a fiber is defined by Eq. (11):

$D_{f}=\frac{J_{x=L}-J_{x=0}}{J_{x=0}} \times 100 \%$

The fiber radius has a dominant effect on $D_{\mathrm{f}}$ according to Eqs. (3) and (8) (Chang and Fane, 2002). Fig. 5 shows the effect of the fiber's inner diameter when the average flux $J_{\mathrm{mi}}$ is $20 \mathrm{~L} \mathrm{~m}^{-2} \mathrm{~h}^{-1}$ and the fiber length is $2 \mathrm{~m}$, values which are very common in large plants. The values of $D_{f}$, calculated from Eq. (11) are $11.23 \%, 4.69 \%, 2.39 \%$ and $1.38 \%$ corresponding to $D_{i}$ of $3,4,5$ and $6 \mathrm{~mm}$. Thus the inhomogeneity of the flux distribution is reduced as inner diameter increases. Considering the packing density and economic factors, $5 \mathrm{~mm}$ is the optimum value of $D_{\mathrm{i}}$.

\subsubsection{Effect of the fiber length}

The fiber length has an influence on the flux distribution according to Eq. (8). When the fiber lengths were $0.20 \mathrm{~m}$, $0.35 \mathrm{~m}$ and $0.52 \mathrm{~m}$, the corresponding $D_{\mathrm{f}}$ are $0.02 \%, 0.07 \%$ and $0.16 \%$. To conclude, the length of the modified glass fiber has little effect on the flux distribution. Long-term experiments prove this conclusion as well. Fig. 6 shows that the stable fluxes and TMP of the three modules with effective length of $0.20 \mathrm{~m}, 0.35 \mathrm{~m}$ and $0.52 \mathrm{~m}$ differ little from each other.

Moreover, the fouling distribution along the $0.52 \mathrm{~m}$-fiber was analyzed after the long-term experiment. Quantitative information was obtained from the total foulants analysis. Fig. 7 shows the axial distribution of the total foulants and local resistances. This confirms that the impact of the length on the flux distribution can be ignored.

\subsection{The determination of the critical time}

The effective area open to the flow will be reduced because of membrane fouling during the operation. When the effective area is reduced to such an extent that the bound and free EPSs along with other sludge constituents agglomerate together on the membrane surface, the cake layer starts to form which will result in the permeability collapse, the local flux in an open pore reaches the level equal to the local critical flux and the critical time is reached. The combination of Eqs. (1), (8) and the experimental values determined by monitoring the changes in trans-membrane pressure and the flux permits a calculation of this value. This enables the frequency of membrane bioreactor cleaning to be optimized.
The calibration process can be described in the following steps:

Step 1: determination of the apparent critical flux ( $U_{\text {mi }}$ (crit)) through flux-stepping method and calculation of the local critical flux $J_{1}(x=l)$ using Eq. (8) with the assumption that the porosity of $31.4 \%$ is not reduced during the short term measurement $J_{\mathrm{mi}}$ (crit).

Step 2: according to Eq. (8), determine the value of $\varepsilon_{\mathrm{c} 1}$ based on the critical time of $15 \mathrm{~d}$ corresponding to $J_{\mathrm{mi}}$ equal to $30.0 \mathrm{~L} \mathrm{~m}^{-2} \mathrm{~h}^{-1}$ in test 1and the value $J_{1}(x=l)$ gained in step 1. Step 3: evaluate the only model parameter K using Eqs. (1), (6) and the experimental results of bound EPSs $\left(C_{b}\right)$ and free EPSs $\left(C_{f}\right)$. Step 4: determine the value of $\varepsilon_{\mathrm{c} 2}$ corresponding to the critical time with the $J_{\mathrm{mi}}$ equal to $15.6 \mathrm{~L} \mathrm{~m}^{-2} \mathrm{~h}^{-1}$ in test 2 and $J_{1}(x=l)$ according to Eq. (8).

Step 5: according to Eqs. (10), simulate the critical time in test 2 with the parameters $K$ and $\varepsilon_{\mathrm{c} 2}$ gained above, and then compare it with the experimentally observed value.

According to the calibration described above, the parameters needed for the models are listed in Table 3. The values of $C_{\mathrm{f}}$ and $C_{b}$ are average representative values during the experiments and they are assumed here to be constant throughout each experiment. Then the critical time is calculated for test 2. The calculated $t_{\text {crit }}$ of $98.6 \mathrm{~d}$ is in very good agreement with the observed values (see data in Fig. 8), even if a slight overestimation by the model was noticed (13.3\%).

\subsection{Performance of the MBR for wastewater treatment}

The performance of the MBR was monitored during test 2 . The initial effluent turbidity was 7.79NTU and five days later the effluent turbidity was about $0.5 \mathrm{NTU}$ where it remained during most of the operation period. At the same time the effluent SS concentrations were nearly zero in most cases while the maximum was $2 \mathrm{mg} \mathrm{L}^{-1}$ (data not shown). In the stable operational period of test 2 , the average COD concentration of the effluent was $29.35 \mathrm{mg} \mathrm{L}^{-1}$ with the average removal efficiency of the whole system of $85.30 \%$. The average $\mathrm{NH}_{4}^{+}-\mathrm{N}$ concentration of the effluent was $1.83 \mathrm{mgL}^{-1}$ with the average removal efficiency of the whole system of $97.26 \%$. Moreover the membrane contributed $23.11 \%$ to the whole system COD removal but just $8.13 \%$ to the $\mathrm{NH}_{4}^{+}-\mathrm{N}$ removal because the membrane had no effect on the retention of free ammonia.

Based on the observed results, it can be concluded that the effluent quality is comparable to that of conventional MBRs. In addition, the MBR using glass fibers as filter media will be a potential beneficial technology for wastewater treatment with the low cost, high strength and good effluent quality.

\section{Conclusions}

In order to solve the problems existing in traditional MBRs, a novel flat grille membrane module using glass fibers as filter media and a membrane bioreactor with this module were studied. The followings are the major conclusions drawn from this study: 
(1) A model, which combines the profile of flux distribution along a fiber with the local flux concept by introducing the membrane porosity, was developed. The simulated apparent critical flux values according to the model were in good agreement with the experimental data.

(2) The membrane module was optimized and the optimized parameters of the module were as follows: the best volume ratio of the membrane solution was 1:2 with a corresponding porosity of $31.4 \%$; the optimal inner diameter was $5 \mathrm{~mm}$ and the fiber length had little influence on the local flux distribution.

(3) The calculated critical time in accordance with the apparent flux of $15.6 \mathrm{~L} \mathrm{~m}^{-2} \mathrm{~h}^{-1}$ was $98.6 \mathrm{~d}$, and the corresponding experimentally observed value was $87 \mathrm{~d}$. Thus the model can be applied to predict the critical time and guide the operation of this MBR.

(4) The effluent turbidity was $0.5 \mathrm{NTU}$, and the average COD and $\mathrm{NH}_{4}^{+}-\mathrm{N}$ removal efficiencies of the whole system were $85.30 \%$ and $97.26 \%$ respectively. Also, the dynamic membrane contributed $23.11 \%$ to the whole system COD removal but just $8.13 \%$ to the $\mathrm{NH}_{4}^{+}-\mathrm{N}$ removal. The performance of this glass fiber MBR was comparable to that of conventional MBRs.

\section{Acknowledgments}

This work was supported by the National 863 Project of China (No. 2006AA06Z333) the National Natural Science Foundation of China (No. 50678168).

\section{R E F E R E N C E S}

Al-Moghaddam, M.R., Satoh, H., Mino, T., 2002. Effect of important operational parameters on performance of coarse pore filtration activated sludge process. Water Science and Technology 46 (9), 229-236.

Bacchin, P., Espinasse, B., Aimar, P., 2005. Distributions of critical flux: modelling, experimental analysis and consequences for cross-flow membrane filtration. Journal of Membrane Science 250 (1-2), 223-234.

Bacchin, P., Aimar, P., Field, R.W., 2006. Critical and sustainable fluxes: theory, experiments and applications. Journal of Membrane Science 281 (1-2), 42-69.

Chang, S., Fane, A.G., 2001. The effect of fibre diameter on filtration and flux distribution - relevance to submerged hollow fibre modules. Journal of Membrane Science 184 (2), 221-231.

Chang, S., Fane, A.G., 2002. Modeling and optimizing submerged hollow fiber membrane modules. AIChE Journal 48 (10), 2203 2212.

China EPA, 2002. Analysis Methods for Water and Wastewater, fourth ed. Chinese Environmental Science Press, Beijing, China (in Chinese).

Chu, L.B., Li, Sh.P., 2006. Filtration capability and operational characteristics of dynamic membrane bioreactor for municipal wastewater treatment. Separation and Purification Technology 51 (2), 173-179.

Cui, Z.F., Chang, S., Fane, A.G., 2003. The use of gas bubbling to enhance membrane processes. Journal of Membrane Science 221 (1-2), 1-35.

Defrance, L., Jaffrin, M.Y., 1999. Comparison between filtrations at fixed transmembrane pressure and fixed permeate flux: application to a membrane bioreactor used for wastewater treatment. Journal of Membrane Science 152 (1-2), 203-210.

Fan, B., Huang, X., 2002. Characteristics of a self-forming dynamic membrane coupled with a bioreactor for municipal wastewater treatment. Environmental Science \& Technology 36 (23), 5245-5251.

Fane, A.G., 2002. Membrane bioreactors: design \& operational options. Filtration \& Separation 39 (5), 26-29.

Fane, A.G., Chang, S., Chardon, E., 2002. Submerged hollow fibre membrane module-design options and operational considerations. Desalination 146 (1-3), 231-236.

Field, R.W., Wu, D., Howell, J.A., Gupta, B.B., 1995. Critical flux concept for micofiltration fouling. Journal of Membrane Science 100 (3), 259-272.

Guglielmi, G., Saroj, D.P., Chiarani, D., Andreottola, G., 2007. Subcritical fouling in a membrane bioreactor for municipal wastewater treatment: experimental investigation and mathematical modeling. Water Research 41 (17), 3903-3914.

Hanft, S., 2006. Membrane bioreactors in the changing world water market. Business Communications Company Inc report, C-240.

Ho, C.C., Zydney, A.L., 2000. A combined pore blockage and cake filtration model for protein fouling during microfiltration. Journal of Colloid and Interface Science 232 (2), 389-399.

Howell, J.A., Chua, H.C., Arnot, T.C., 2004. In situ manipulation of critical flux in a submerged membrane bioreactor using variable aeration rates, and effects of membrane history. Journal of Membrane Science 242 (1-2), 13-19.

Ji, L., Zhou, J.T., 2006. Influence of aeration on microbial polymers and membrane fouling in submerged membrane bioreactors. Journal of Membrane Science 276 (1-2), 168-177.

Kiso, Y., Jung, Y.J., Ichinaril, T., Park, M., Kitao, T., Nishimura, K., Min, K., 2002. Wastewater treatment performance of a filtration bio-reactor equipped with a mesh as a filter material. Water Research 34 (17), 4143-4150.

Kuberkar, V.T., Davis, R.H., 2000. Modeling of fouling reduction by secondary membranes. Journal of Membrane Science 168 (1-2), 243-258.

Le-Clech, P., Jefferson, B., Chang, I.S., Judd, S.J., 2003a. Critical flux determination by the flux-step method in a submerged membrane bioreactor. Journal of Membrane Science 227 (1-2), 81-93.

Le-Clech, P., Jefferson, B., Judd, S.J., 2003b. Impact of aeration, solids concentration and membrane characteristics on the hydraulic performance of a membrane bioreactor. Journal of Membrane Science 218 (1-2), 117-129.

Madecl, A., Buisson, H., Aïm, R.B., 2008. Aeration to Enhance Membrane Critical Flux. http://www.sffiltration.org/publi-1.htm.

Ognier, S., Wisniewski, C., Grasmick, A., 2004. Membrane bioreactor fouling in sub-critical filtration conditions: a local critical flux concept. Journal of Membrane Science 229 (1-2), 171-177.

Saroj, D.P., Guglielmi, G., Chiarani, D., Andreottola, G., 2008. Subcritical fouling behavior modelling of membrane bioreactors for municipal wastewater treatment: the prediction of the time to reach critical operating condition. Desalination 231 (1-3), 175-181.

Shimizu, Y., Shimodera, K.I., Watanabe, A., 1993. Cross-flow microfiltration of bacterial cells. Journal of Fermentation and Bioengineering 76 (6), 453-500.

Wang, Z.W., Wu, Z.C., Yu, G.P., Liu, J.F., Zhou, Z., 2006. Relationship between sludge characteristics and membrane flux determination in submerged membrane bioreactors. Journal of Membrane Science 284 (1-2), 87-94.

Williams, M.D., Pirbazari, M., 2007. Membrane bioreactor process for removing biodegradable organic matter from water. Water Research 41 (17), 3880-3893.

Wu, D.X., Howell, J.A., Field, R.W., 1999. Critical flux measurement for model colloids. Journal of Membrane Science 152 (1), 89-98. 
Yeo, P.S.A., Law, W.K.A., Fane, A.G., 2006. Factors affecting the performance of a submerged hollow fiber bundle. Journal of Membrane Science 280 (1-2), 969-982.

Yoon, S.H., Kim, H.S., Yeom, I.T., 2004. Optimization model of submerged hollow fiber membrane modules. Journal of Membrane Science 234 (1-2), 147-156.

Zhou, X.H., Shi, H. Ch., Cai, Q., He, M., Wu, Y.X., 2008. Function of self-forming dynamic membrane and biokinetic parameters' determination by microelectrode. Water Research 42 (10-11), 2369-2376.

\section{Nomenclature}

$\mathrm{A}_{e}$ : effective area $\left(\mathrm{m}^{2}\right)$

$\mathrm{A}_{a}$ : apparent area $\left(\mathrm{m}^{2}\right)$

$\varepsilon$ : porosity
$\mathrm{C}_{b}$ : bound EPS $\left(\mathrm{g} \mathrm{m}^{-3}\right)$

$\mathrm{C}_{f}$ : free EPS $\left(\mathrm{g} \mathrm{m}^{-3}\right)$

$\mathrm{K}$ : coefficient of fouling propensity $\left(\mathrm{m}^{2} \mathrm{~h} \mathrm{~g}^{-2}\right)$

$\mathrm{J}_{m i}$ (crit): apparent critical flux

$\mathrm{J}_{1}(\mathrm{x}=1)$ : local critical flux at the outlet

$J_{m i}$ : averaged imposed flux

l: fiber length $(\mathrm{m})$

$\mathrm{R}_{\mathrm{i}}$ : fiber inner radius $(\mathrm{mm})$

$\mathrm{D}_{i}$ : fiber inner diameter $(\mathrm{mm})$

$\mathrm{R}_{m}$ : membrane resistance $\left(\mathrm{m}^{-1}\right)$

$\lambda$ : coefficient

$\mathrm{d}_{\mathrm{i}}$ : fiber inner diameter $(\mathrm{mm})$

$\mathrm{x}$ : axial coordinate $(\mathrm{m})$

$\mathrm{u}$ : flow velocity through membrane surface $\left(\mathrm{m} \mathrm{s}^{-1}\right)$

$\mathrm{K}_{\mathrm{L}}$ : filtration constant $\left(\mathrm{kg}^{0.5} \mathrm{~m}^{-2.17} \mathrm{~Pa} \mathrm{~s}\right)$

$\mathrm{V}_{\mathrm{L}}$ : back transport velocity $\left(\mathrm{m} \mathrm{s}^{-1}\right)$ 